\title{
Incídentes de integración en Centroamérica y Panamá, 1952-1958
}

\author{
Víctor L. Urquidi, El Colegio de Mexico
}

\section{Prólogo protoautobiográfico}

Mis antecedentes con Centroamérica son muy lejanos. Mi abuelo inglés, Thomas Percy Bingham, con motivo de su constante navegar por océanos de Asia como sobrecargo en buques de pasajeros de la línea $\mathrm{P} \& \mathrm{O}$, había establecido su hogar en Melbourne, Australia. Allí nacieron hijos e hijas, entre éstas mi madre, Beatrice Mary. En 1898, el señor Bingham decidió buscar nuevas oportunidades en Greytown (San Juan del Norte), costa atlántica de Nicaragua, donde se iniciaban obras para construir un canal interoceánico. A falta de escuela adecuada, la enseñanza a los hijos la impartía mi abuela, Julia Sofía, originaria de Dover, Inglaterra, quien hablaba además español, catalán y francés. La familia conoció de cerca la naturaleza y la comunidad de ese trópico despoblado. Después vivieron en Managua, en época de revoluciones y asonadas. Mi madre fue enviada en 1916 a Nueva York a estudiar enfermería. Allí conoció a mi padre, el ingeniero Juan Francisco Urquidi, nacido en la ciudad de México, de familia chihuahuense, quien después de episodios políticos prodemocráticos al lado de Francisco 1. Madero, tuvo que ir en 1913 al exilio, al ser éste asesinado por órdenes de Victoriano Huerta. Participó después en la representación del gobierno de Venustiano Carranza en Washington, y al fin se trasladó a Nueva York, donde fundó una revista mensual en español. Conoció a mi madre porque ella, siendo bilingüe, era asignada en su hospital a atender a pacientes de habla española; un amigo mexicano común los presentó. Casaron en Filadelfia en 1917; en 1918, recién firmado el armisticio en Compiégne, y a invitación del recién nombrado Ministro de México en Francia, Alberto J. Pani emprendieron el viaje a París. En el suburbio de Neuilly, en mayo de 1919, abrí los ojos por primera vez. Mi padre tuvo el cuidado, conforme a sus privilegios diplomáticos, de garantizar legalmente mi nacionalidad mexicana.

No supe de Centroamérica hasta mediados de 1927. Tras más de tres años de estadía en Bogotá -donde mi padre había ejercido la representación diplomática de México-, descendimos por el río Magdalena y nos embarcamos en Santa Marta para Nueva York, con escala en Puerto Limón, Costa Rica. Tengo bien grabado el recuerdo. Además, en casa se hablaba a veces de Nicaragua, porque allí residía la hermana mayor de mi madre, y se recordaban muchas amistades. En 1928 mi padre fue trasladado a El Salvador. Mi madre me dejó interno en una escuela en México con la esperanza de que mejorara mi conducta. Mi padre aguantó poco la separación y vino por mí al finalizar el año escolar; partirnos en tren hasta Tapachula y la margen del río Suchiate, frontera con Guatemala, donde subimos a otro tren que nos llevó a lo que me pareció una majestuosa ciudad, la capital, donde pasamos la noche. En la madrugada seguimos en un automóvil de la época por una carretera no pavimentada hasta San Salvador, pasando por Santa Ana. 
Mis recuerdos de San Salvador en esa época son muchos: la escuela, dirigida por un profesor mexicano, era magnífica, excepto que me peleé a golpes con un compañero de apellido Dutriz porque insultó a los mexicanos; por otro lado, aprendí a jugar béisbol en el Campo de Marte y golf en el Country Club; por primera vez escuché radio internacional (principalmente, estática); pasé un par de semanas en una finca azucarera en Sonsonate, la mayor parte del tiempo montado a caballo; conocí fincas cafetaleras y me hice de amigos, con uno de los cuales tengo aún contacto. Subí por primera vez a un avión trimotor en el aeropuerto de llopango (10 minutos de vuelo sobre la capital). En San Salvador nos acostumbramos a los frecuentes sismos que hacían temblar y rechinar toda la casa.

El incidente más notable -cuya importancia no percibí a su tiempo- fue que nuestros padres nos llevaron a mí y a mis hermanas a un encuentro que se tuvo en una estación de tren en las cercanías de San Salvador para atender acompañado por el Ministro de Relaciones Exteriores y el Ministro de Defensa de El Salvador, y otros funcionarios, a César Augusto Sandino. Este viajaba a México con parte de su estado mayor, a efectuar consultas con personalidades del gobierno mexicano. Se sacó una foto memorable, en que aparecemos todos: Sandino, Farabundo Martí y otros acompañantes, los funcionarios salvadoreños, el Ministro de México y su familia -foto que muchas veces ha sido reproducida en la prensa de El Salvador, y de la que tengo copia. Además, mi madre había llevado su Kodak de la época y tomó varias fotos del general Sandino, alguna de las cuales ha sido publicada y difundida. Ella, en Nicaragua, había sido amiga de la madre de Sandino y lo había conocido a él y a otros familiares. En otra ocasión, un oficial al servicio de Sandino había pasado por la Legación de México con un pañuelo de seda que tenía inscrita una carta dirigida a un personaje político mexicano; mi madre fotografió el pañuelo, y me di cuenta de la firma "A.C. Sandino", que me inspiró después a imitar la grafía de la $\mathrm{A}$ unida a la $\mathrm{C}$, para combinar en mi propia firma la $\mathrm{V}$ con la $\mathrm{L}$ en secuencia más natural. En la escuela se menciona también a Sandino y leíamos artículos de prensa de Vicente Sáenz

Designado mi padre Ministro de México en la República Oriental del Uruguay, tomamos él y yo en 1930 el recién inaugurado tren internacional, para Zacapa y Puerto Barrios. Embarcamos con destino a Nueva Orleans, de donde seguiríamos en tren a Nueva York, y en barco inglés a Montevideo (18 días, con escala en Río de Janeiro y Santos). En el barco aprendí algo de portugués de una pasajera brasileña. Mi madre y mis hermanas habían salido antes a México, y nos alcanzarían más tarde en Montevideo tras también largo viaje por tren y barco. A principios de 1932, vía Madrid, volvimos a México, y emprendimos a principios de 1935 la travesía atlántica a España al ser nombrado mi padre Ministro-consejero en la Embajada de México en Madrid. En 1936 salí a estudiar a Londres, ingresando a la LSE, donde obtuve la licenciatura en 1940, en plena guerra, poco antes de los peores bombardeos. A mis padres les tocó el principio de la guerra civil española, hasta que salieron de vuelta a México por disposición del gobierno mexicano, vía Valencia, Port Bou y París, en marzo de 1937. Los primeros siete meses de la guerra de España fueron una experiencia traumática para la familia: mis padres en Madrid, mis hermanas en Portugal y yo en Londres. Mary B. de Urquidi relató hace años los trágicos 
acontecimientos madrileños en un libro, con referencia a la labor hospitalaria que ella, por su profesión, llevó a cabo, y al problema de la Embajada de México de dar asilo y albergue a más de mil refugiados.

\section{Mi encuentro con Raúl Prebisch}

Trabajaba yo en 1943 en el Departamento de Estudios Económicos del Banco de México cuando supe que el doctor Raúl Prebisch, Gerente del Banco Central de la República Argentina, había sido obligado a dimitir. El Director del Banco de México, Eduardo Villaseñor, a instancia de Daniel Cosío Villegas, lo invitó de inmediato a efectuar una visita de unas tres semanas, para dar charlas sobre su experiencia corno banquero central. Confieso que no tenía yo la menor idea de quién era, pero conocíamos en el Departamento de Estudios Económicos publicaciones financieras argentinas, en particular los informes anuales del Banco Central. Tuve oportunidades de conversar con don Raúl sobre sus experiencias en la Sociedad de Naciones, el Ministerio de Hacienda, el Banco de la Nación y el Banco Central. Mi trabajo abarcaba entonces el estudio de las propuestas de Bretton Woods (1942-1944) y otras para la postguerra, y cubría muchos aspectos de la economía y las finanzas internacionales. Había yo leído cantidad de informes, artículos y libros.

En 1944, Raúl Prebisch fue invitado de nuevo por el Banco de México, para ofrecer un curso a funcionarios, economistas y personal de la banca y las finanzas públicas. Fui designado su enlace y acompañante y me pude beneficiar de largas conversaciones con él; además, don Raúl fue invitado a varios viajes al interior de México en compañía de funcionarios. También presentó en El Colegio de México, en un seminario sobre América Latina, un trabajo, ya clásico, sobre la vulnerabilidad económica de los países de América Latina. $1 /$

En 1946, se le invitó una vez más, a título personal, a la Primera Reunión de Técnicos de Banca Central del Continente Americano (incluidos Canadá y Estados Unidos), que por encargo del Director General del Banco de México me tocó organizar. De esa primera reunión saldría más tarde, en 1952, con apoyo de otros bancos centrales, la creación del Centro de Estudios Monetarios Latinoamericanos (CEMLA), basado en una propuesta de Javier Márquez (con la que nunca estuvo de acuerdo Raúl Prebisch y que motivó, según me consta, un distanciamiento entre ellos). En 1952, también, en su calidad de Secretario Ejecutivo de la CEPAL, el doctor Prebisch asistió a una reunión del Consejo Económico y Social de las Naciones Unidas efectuada en México.

Entre 1948 y 1951, tuve leves contactos con él cuando pasaba por México. No recuerdo que jamás hayamos hablado de Centroamérica, pero en junio de 1951, a raíz del cuarto período de sesiones de la CEPAL, efectuado en México, me preguntó si me interesaría ingresar al personal de economistas de la CEPAL, en una oficina regional que se proyectaba establecer en México, con referencia especial a asuntos centroamericanos. Estaba yo por concluir un compromiso con el Banco de México y Nacional Financiera, 
terminando de redactar algunos capítulos de un estudio conjunto propalado por el Gobierno de México y el Banco Mundial sobre el desarrollo económico de México y la capacidad para absorber capital del exterior. Pensándolo bien, pues además me hallaba en situación incómoda en el Banco de México, acepté el ofrecimiento, para iniciar labores en octubre de 1951.

El sueldo me convenía y el programa despertó sin duda en mí un interés latente por volver a conocer Centroamérica. De ésta sabía yo poco, pues en Bretton Woods, donde en 1944 había formado parte de la delegación mexicana, y en el Banco Mundial, donde presté mis servicios de 1947 a 1949, no destacaban los países centroamericanos. Sin embargo, en Bretton Woods había conocido y trabado amistad con Manuel Noriega Morales, único representante de Guatemala en la lista de delegados, descrito como "estudiante de postgrado, Universidad Harvard", y en Washington, más tarde, conocí a algunos economistas de Nicaragua y El Salvador, entre éstos en particular a Jorge Sol Castellanos, que trabajaba en el FMI con Robert Triffin.

En el cuarto período de sesiones de la CEPAL en 1951, el Programa de Integración Económica del Istmo Centroamericano, según se le designó, había sido propuesto por los representantes de Centroamérica, entre ellos Manuel Noriega Morales (Guatemala), Jorge Sol Castellanos (El Salvador) y Enrique Delgado (Nicaragua), y aprobado en sesión plenaria como resolución $9(1 \mathrm{~V})$. El proyecto me pareció de gran interés. Había yo estudiado comercio internacional, política arancelaria y política de desarrollo, y además los principios de la integración económica europea: el Benelux (más adelante, la Comunidad del Carbón y del Acero, la Comunidad Económica Europea). Me entusiasmaba la idea de colaborar en semejante empeño.

\section{III.. Primeras tareas en Centroamérica}

La CEPAL constituyó la oficina regional en México (designada la Subsede), en julio, a cargo de Eugenio Castillo. Antes de que yo ingresara en octubre, había sido enviado a la Subsede el periodista financiero argentino Roberto Katz, para hacer un recorrido por los cinco países centroamericanos en busca de datos e información preliminar.

En algún momento hacia fines del año, Eugenio Castillo hizo un viaje formal, acompañado de Francisco Giner de los Ríos, para cambiar impresiones con los ministros de Economía y otros funcionarios, ya que, con arreglo a la resolución 9(1V) de la CEPAL, se crearía el Comité de Cooperación Económica del Istmo Centroamericano (en adelante CCEICA) destinado a dar vida al Programa de Integración Económica y diseñar instrumentos para lograrlo.

El panorama político en Centroamérica era bastante variado, desde un gobierno de izquierda del presidente Arbenz en Guatemala, un presidente militar, el coronel Osorio, en El Salvador, un gobierno sucesor del dictador Carías en Honduras, la presidencia del general Anastasio Somoza en Nicaragua y un gobierno democrático en Costa Rica. Creo 
que Castillo vio con bastante escepticismo la perspectiva de la integración económica, no obstante la existencia de dos o tres viejos tratados bilaterales de comercio y, en particular, el antecedente de la Federación, las Provincias Unidas de América Central, vigente durante un corto periodo en la primera mitad del siglo XIX, más algunos antecedentes sobre unión centroamericana en el XX, de naturaleza más bien política.

Se había creado en 1951 una organización política centroamericana, la Organización de Estados Centroamericanos (la ODECA), inspirada en la OEA, pero algunos de los nuevos ministros de economía, los que asistieron a la conferencia de la CEPAL y produjeron la iniciativa citada, preferían que se creara un organismo independiente y objetivo, despolitizado, con secretaría técnica en la CEPAL, para ocuparse de la integración económica, hacer los estudios necesarios y llevarlos posteriormente a acuerdos y compromisos de alcance centroamericano. Habían tenido en cuenta además los mecanismos de los comienzos de la Comunidad Económica Europea.

La CEPAL no tenía experiencia en el manejo de un comité intergubernamental como el propuesto -como ya existían en la Comisión Económica de las Naciones Unidas para Europa- y carecía además de personal conocedor de la economía de Centroamérica, y aun de información sistematizado. Castillo tal vez no fue muy persuasivo, y, regresó a la Subsede con las manos vacías. Sin embargo, Raúl Prebisch había empeñado su palabra. Cuando yo ingresé a trabajar en la Subsede, tuve que comenzar casi desde cero, en mi calidad de jefe de la oficina de estudios, a las órdenes de Castillo.

Me hice unos planteamientos básicos acerca de lo que podía ser un proceso de integración con creación de una unión aduanera y liberación del comercio, en un marco de desarrollo industrial como proceso de sustitución de importaciones a escala regional, lo cual a su vez requeriría un desarrollo importante de infraestructura. Propuse a Castillo la contratación de Cristóbal Lara para ayudarme, sobre todo en la parte industrial, y se contrataron dos expertos agrícolas -pues no bastaban las correrías de Katz en un viejo Chevrolet, con su caña de pescar atada a un costado y su cámara colgada al cuello.

Cristóbal y yo elaboramos los anteproyectos y los enviamos al doctor Prebisch en Santiago para su opinión y pedimos a Castillo sugerir a don Raúl que sería oportuno que éste encabezara una misión de la CEPAL a Centroamérica el mes de marzo de 1952. Entre tanto, un golpe de suerte (para nosotros) nos permitió contratar a José Antonio Mayobre, recién emigrado de Venezuela, para una parte de los estudios, entre ellos una visión de lo que podría aportar a Centroamérica una institución de investigación tecnológica (un proyecto anterior de Naciones Unidas había resultado fallido).

Partimos a Guatemala: Prebisch, Castillo, Mayobre, Ramón Fernández y Fernández y un ingeniero agrónomo, con un programa preparado de entrevistas a los más altos niveles y de reuniones de trabajo con economistas y técnicos. Fue un viaje un tanto apresurado, pero apoyado en voluntad política en los países, coordinado por los ministros de Economía, y muy fructífero en intercambio de puntos de vista. Cenamos algunos de nosotros con el presidente Arbenz y su esposa, tuvimos comidas y cenas, y reuniones largas, con funcionarios de las áreas financiera, monetaria y económica, agraria y social, 
estadística y de política exterior de Guatemala. Hubo debates entre Prebisch y algunos dirigentes políticos. Fueron días fructíferos, y partimos de madrugada a San Salvador, donde nos esperaba en el aeropuerto el ministro de Economía, Jorge Sol, con su comitiva.

Instalados en el hotel, después de un descanso, empezamos ese mismo día las entrevistas. Prebisch tenía contraída una entrevista al día siguiente a las 9 horas con el Ministro de Hacienda, a la que llegó puntualmente. Jorge Sol era evidentemente el alma de la idea de la integración y contaba con buena base de conocimientos y experiencias, así que pudimos hablar con él de estrategias y mecanismos. Hubo una entrevista con el presidente Osorio, en compañía de Jorge Sol. Hablamos también con dirigentes empresariales.

La etapa subsiguiente fue Tegucigalpa, con el ministro de Economía, Marco A. Batres, amable pero sin mayor interés en el tema; en cambio, el presidente del Banco Central, Roberto Ramírez, abogado, empresario agrícola, ex-juez y ex-futbolista, apoyó el programa sólidamente, como lo demostró durante años. Los pelos en la sopa eran sin embargo dos economistas, uno italiano y otro italoamericano, que, con un ojo puesto en futuras prebendas y negocios, abogaban por el libre comercio internacional de Honduras con el resto del mundo, sin ver en la integración nada provechoso -a pesar de que existía comercio bilateral en manufacturas con El Salvador: telas hondureñas por calzado salvadoreño. En Tegucigalpa hacíamos después de la cena agradables caminatas por los callejones y calles empedrados, en medio de un silencio casi sepulcral.

La visita a Nicaragua giró alrededor de Enrique Delgado, el ministro de Economía, y sus asesores, pero inevitablemente se situó bajo la sombra del dictador Anastasio Somoza, padre. Al fin se obtuvo la audiencia con él, una cena en la casa-hacienda de un ingenio azucarero de su propiedad, en plena molienda de caña; asistimos, según recuerdo, Prebisch, Castillo, Enrique Delgado, Mayobre y yo. Creo que se habló de muchas cosas, pero muy poco de integración centroamericana, pues esta era vista por Somoza a su modo. No era fácil .por lo demás, tratar los asuntos ordinarios en las oficinas gubernamentales de Managua. Raymond Etchats quien años después fue el representante de la Junta de Asistencia Técnica de las Naciones Unidas para Centroamérica, decía que en un descuido, con los ventiladores girando a toda marcha, en medio del infernal calor de la ciudad, podía volar por la ventana el PIB recién calculado. Una noche, en etapa posterior, en una cena-baile que ofreció el general Somoza a los ministros de Economía en conocido club, al entrar me di cuenta de que nunca había visto juntos tantos "kepís" militares en un guardarropas -y detrás de cada cortina estaba un guardia con ametralladora en la mano mientras se cenaba y bailaba. En otra ocasión nos llevaron a pasear en un barco mercante de la flota centroamericana (de Somoza) todo un día en aguas del Pací́fico.

Continuando con la gira de Prebisch, la llegada a San José, Costa Rica, fue un gran contraste con Nicaragua. Sólo entraban al aeropuerto los pequeños DC-3, en una pista no pavimentada. El hotel en San José resultaba bastante modesto; se tenía la impresión de estar en un pequeño e id́lico poblado de los bajos Alpes, entre gente que no parecía centroamericana sino europea. El día anterior, el presidente de Costa Rica, quien se 
dirigía todos los días a pie de su domicilio a la también aldeana casa presidencial, había sido atropellado por un ciclista. Me dije: a éste lo van a fusilar (pensando en un ambiente más bien mexicano); pero no, sino que lo regañaron y lo multaron, todo el mundo encontró el asunto bastante gracioso y allí terminó la cosa. El ministro de Economía, el ingeniero Alfredo Hernández, nos atendió muy correctamente, y nos llevó a visitar su finca ganadera por el rumbo de Cartago: nos entrevistamos con algunos políticos, banqueros e industriales, así como con asesores, y creo, pero no recuerdo bien, que vimos a don Pepe Figueres (en años posteriores trabé excelente amistad con él). Partimos con ciertas dudas, con la impresión de que los industriales no tenían interés en la integración, pero pensando que tal vez esperaban que se presentaran condiciones favorables en general.. El principal problema concreto de la época era que los artesanos del calzado se oponían al establecimiento de una fábrica moderna. En Costa Rica como en Honduras, pesaban también mucho los intereses de las empresas bananeras extranjeras. Costa Rica, pese a su apoyo y entusiasmo, no llegó a ratificar los primeros tratados y convenios de integración y libre comercio centroamericanos.

Durante el camino, en El Salvador, Eugenio Castillo había recibido un cablegrama de Fulgencio Batista, con quien tenía amistad, para ir a La Habana a ocupar un alto puesto financiero. Para cuando llegamos a Panamá, advertimos que desde el primer momento estaba convencido de la conveniencia de aceptar. En Panamá tuvimos interesantes conversaciones con altos funcionarios y banqueros, quienes veían al resto del Istmo Centroamericano a bastante distancia y con cierto desdén, sin tener con los demás países vínculos económicos interesantes; nos llevaron en especial a conocer la Zona Libre de Colón Veían a Panamá como un intermediario comercial y financiero Nos llamó la atención que circulaba el dólar-billete, aunque había moneda fraccionaria panameña, y que gran parte del comercio estaba en manos de ciudadanos de la India.

Antes de terminar allí el recorrido, la última noche, el doctor Prebisch nos invitó a hacer un balance a fin de encauzar las actividades próximas de la Subsede hacia una primera reunión del CCEICA, proponiendo que fuera en Tegucigalpa a fin de fortalecer el interés de los posibles escépticos. Por último, Prebisch me invitó a reunirme con él y con Castillo. Fui testigo de una severa reprimenda de Prebisch a este último por lo poco auspiciosa que había sido la etapa preparatoria inicial, por su escasa participación e interés en las muchas reuniones y conversaciones entabladas durante la reciente gira, y por su evidente deseo de irse a Cuba. Castillo, que era muy emocional, derramó lágrimas e hizo efusivos elogios de Prebisch y de su lealtad, previo al resultado inevitable: que presentaría de inmediato su renuncia a la CEPAL, previendo sólo el tiempo necesario para quitar casa en México y hacer maletas y baúles.

\section{El primer avance hacia la integración}

De regreso en la Subsede nos pusimos todos a trabajar, preparando documentos sobre los objetivos de la integración y de la creación de una zona de libre comercio, los mecanismos necesarios, el apoyo que ofrecería la secretaría de la CEPAL y el que podría 
provenir de los órganos de asistencia técnica del Sistema de las Naciones Unidas, a través de la Junta de Asistencia Técnica (TAB) que presidía David Owen en Nueva York. Se previó en especial la necesidad de contar con más información. Habría una serie de visitas de trabajo. Mayobre redactaría la propuesta de crear el Instituto de Investigación Tecnológica (que después se llamaría el ICAITI) como organismo constituido con las Naciones Unidas por los cinco gobiernos centroamericanos.

Por la vía de la Administración de Asistencia Técnica en Nueva York, que dirigía en su parte latinoamericana Gustavo Martínez Cabañas, antes el primer secretario ejecutivo de la CEPAL en Santiago, se formuló, con la ayuda de Enrique Tejera, de Venezuela, la creación de una Escuela Superior de Administración Pública de América Central (ESAPAC).

La Conferencia en Tegucigalpa se llevó a cabo con todo éxito el mes de agosto, con la presencia de los cinco ministros de Economía, del doctor Prebisch y de representantes de asistencia técnica de las Naciones Unidas. Se aprobaron las resoluciones necesarias para que el programa de integración se pusiera en marcha. Centroamérica jamás había recibido un apoyo institucional, el de Naciones Unidas, tan congruente. Por la secretaría, Cristóbal Lara y yo trabajamos toda la noche en la redacción del informe, que se aprobó la mañana siguiente (Jorge Sol entró a las 2 de la madrugada a ponernos una botella de whisky sobre la mesa; creo que no la despreciamos -ésta era parte de la metodología de integración a la centroaméricaine y además aprendimos que la región tenía ya una moneda común: el whisky).

Prebisch me nombró director de la Subsede en reemplazo de Castillo, Mayobre se convirtió en Representante de la Junta de Asistencia Técnica para Centroamérica, contratamos a otros economistas y expertos agrícolas, nos reforzó la sede de Santiago, y nos llegaron poco a poco expertos bajo el programa de asistencia técnica de la FAO, la OIT, la UNESCO, y otros organismos para encargarse de determinados estudios. La Conferencia de Tegucigalpa apoyó la idea de marchar hacia un mercado común, con arancel externo común. Se crearon comités especiales, de los cinco países, con frecuencia con un observador de Panamá, para tratar sobre el comercio y los aranceles, el transporte, la cooperación agrícola (que tuvo a su cargo más adelante Carlos Manuel Castillo), la educación y la capacitación, la integración eléctrica, la vivienda, la estadística y otros temas. La FAO designó expertos forestales y de fabricación de celulosa, quienes al cabo de tres años produjeron propuestas (que nunca se han cumplido) de proteger los bosques y de poner en marcha una planta de celulosa en Honduras; a estos expertos, así como a muchos otros de distintos organismos de las Naciones Unidas, les teníamos que revisar cuidadosamente sus informes, sobre todo para hacerlos compatibles y congruentes con los propósitos del Programa de Integración -no fue siempre tarea fácil.

En materia de comercio intracentroamericano, hubo trabajos pesados y minuciosos, como el de homologar las listas arancelarias de los cinco países bajo una nueva nomenclatura, la NAUCA, en que colaboraron Santiago Macario y Rafael Izquierdo. Recuerdo bien la primera negociación preliminar multilateral de las listas de productos propuestos para el libre intercambio bajo un arancel común: inventamos la metodología sobre la marcha. 
En cuanto a infraestructura, el estudio sobre el transporte fue de carácter pionero, en manos de César Elías, del Perú, y colegas de Uruguay, Francia y el Departamento de Transporte de Naciones Unidas, entre ellos Stanislav Ambrosek. Alfonso Santa Cruz vino de Santiago a colaborar, y después de un seminario final en San José, entre él y yo ayudamos a hacer el informe que se publicó. Un experto mexicano se encargó de un estudio y recomendaciones para la adopción del sistema métrico decimal en Centroamérica. Una experta francesa elaboró un proyecto de convenio multilateral sobre la circulación transfronteriza de vehículos de motor; el principal obstáculo era el temor de que pasaran camiones cargados de armas. Un demógrafo norteamericano, contratado por Naciones Unidas, calculó las primeras proyecciones demográficas de las cinco repúblicas y formuló recomendaciones sobre política de población.

De todas estas tareas, y sobre todo de los avances hacia el tratado multilateral de libre comercio, la Secretaría informaba a los períodos de sesiones bienales de la CEPAL y auxiliaba a los representantes centroamericanos en la redacción de los proyectos de resolución correspondientes. Los estudios se sometían previamente a los comités de trabajo y al CCEICA integrado por los ministros.

La integración industrial constituía en verdad el meollo del Programa, como parte de un proceso de desarrollo mancomunado que se esperaba asumiría la región centroamericana. Exploramos con Cristóbal Lara y un experto de Naciones Unidas, Edward Wygard, las posibilidades concretas de la integración industrial complementaria de los países centroamericanos por medio de plantas de escala suficiente para abastecer el mercado regional o parte de él, y elaboramos un proyecto -finalizado en Managua- de Convenio sobre un Régimen de Industrias Centroamericanas de Integración, en que aportaron mucho desde el punto de vista técnico el ministro de Economía de Nicaragua, Enrique Delgado, y sus asesores. Se creó una Comisión Centroamericana de Integración Industrial en que estuvieron representados tanto los gobiernos como los sectores empresariales para explorar posibilidades. Nunca antes se habían reunido con ese propósito.

Sin embargo, la idea de la integración industrial acabó por ser en gran parte torpedeada por el Departamento de Estado de Estados Unidos. Funcionarios de esa dependencia manifestaban que apoyaban la idea de la integración y un mercado común centroamericano, pero no la forma en que los gobiernos, con ayuda de la Secretaría de la CEPAL, la estaban promoviendo. Estados Unidos, como miembro de la CEPAL, estaba informado, como todos los demás países, de las actividades del CCEICA iniciadas en 1952.

En febrero de 1959, cuando ya no trabajaba yo en la CEPAL, fui entrevistado en México por dos funcionarios del Departamento de Estado, los señores Henry Turkel e Isaiah Frank, quienes, en consecuencia de instrucciones del Secretario Adjunto de Estado para América Latina, Thomas Mann, promovían la idea de olvidarse de la CEPAL y sus mecanismos de integración y de proponer un tratado de comercio libérrimo entre El Salvador y Honduras, con exclusión de los demás países. Me di cuenta de que efectivamente no les interesaba nada de lo que se había logrado con la CEPAL en materia 
institucional, de infraestructura y de negociaciones. Les molestaba en especial el Tratado Multilateral de Libre Comercio e Integración firmado en Tegucigalpa en junio de 1958 que fue el último acto que me correspondió como funcionario de la CEPAL-, y más aún consideraban inconveniente el Convenio sobre el Régimen de Industrias Centroamericanas de Integración, que consideraban contrario a la libre empresa.

A pesar de que traté de hacerles ver que estos instrumentos eran parte de un conjunto de convenios y compromisos, en un Programa bastante completo apoyado por las Naciones Unidas y discutido en los cinco países, ellos reportaron después a sus superiores una posición ambigua de mi parte, lo cual es totalmente falso. Yo me enteré de esto apenas hace unos pocos años, por un trabajo de investigación de un profesor de la Universidad Rutgers, quien había logrado consultar abundante documentación confidencial en archivos norteamericanos para un minucioso estudio sobre el interés de Estados Unidos en la integración centroamericana. $\underline{2 /}$

Turkel y Frank me dijeron que iban a Guatemala a entrevistarse con Alberto Fuentes Mohr, Ministro de Integración Económica Centroamericana en el gobierno del presidente Miguel Ydígoras, pero como su propósito real era promover un tratado de libre comercio solamente entre El Salvador y Honduras, pude darle el pitazo a tiempo, por teléfono, a Alberto, quien supo manejar muy bien la posición de Guatemala. El resultado, meses después, fue la firma de un Tratado Trilateral de Asociación Económica que no tuvo en todo caso vigencia real. Pero al mismo tiempo se reavivaron las fuerzas impulsoras del arreglo multilateral, habiendo sido el de 1958 ratificado por Guatemala. La Subsede de la CEPAL, encabezada entonces por Alfonso Santa Cruz, consiguió que en 1960 se firmara en Managua un nuevo Tratado General de Integración Económica Centroamericana. A diferencia del de 1958, al cual sólo otorgaba el libre comercio a una lista positiva, bastante limitada, de productos, el de Managua abría al libre comercio toda la producción centroamericana salvo una lista negativa de productos sujeta a nuevas negociaciones. Parece que este procedimiento logró eliminar la oposición de Estados Unidos. Esta parte de la historia ya no me tocó de cerca -estaba yo en otras cosas en México.

El tratado multilateral de 1960 fue el que rigió la extraordinaria expansión del comercio intracentroamericano hasta 1969. El Régimen de Industrias de Integración casi no tuvo vigencia. Sin embargo, se incrementó la inversión extranjera directa en Centroamérica para disfrutar del Tratado Multilateral. Una vez, en un vuelo de Panamá a México, un empresario norteamericano, sin saber quien era yo, me explicó la integración centroamericana y cómo su empresa, de productos farmacéuticos, se había beneficiado; le pregunté cómo habían escogido su sede, Guatemala, y su respuesta fue: es el mercado más grande de los cinco.

Independientemente de las tensiones internas que haya generado el libre comercio en Centroamérica, lo que interrumpió el proceso fue el conflicto entre El Salvador y Honduras en 1969. En esos días, regresando de Sudamérica, hice por cuenta propia escala en El Salvador, Honduras y Guatemala para hablar con mis viejos amigos sobre la posibilidad de que se reanimara el Tratado de 1960, y el programa en su conjunto, pero no existían condiciones suficientes, y había decaído bastante el ánimo. Costa Rica y 
Honduras no participaban en absoluto.

Creo que, a lo largo del tiempo, se perdió una gran oportunidad histórica, pero como lo habían advertido Ernst Haas y Philippe Schmitter en más de una ocasión, el programa carecía de consensos y asideros políticos, es decir, habíamos todos actuado como técnicos, creyendo ingenuamente que lo político se arreglaba solo o que los propios centroamericanos lo podían arreglar.

Además, los compromisos y los mecanismos institucionales eran muy complicados. No nos faltaron ocasiones de enfrentarnos con la mini-Realpolitik de Centroamérica. Primero, la poca disposición inicial de Estados Unidos hacia la idea de un desarrollo con integración en un contexto de planeación de una nueva etapa de industrialización. Segundo, su regular desconfianza de todo lo que hacía la CEPAL. Tercero, la probable oposición sorda y potente de intereses como los de la United Fruit (de la que tuvimos evidencias) y posiblemente otros tanto centroamericanos como extranjeros. Cuarto, el síndrome Somoza: un día estaba yo en su despacho en Managua, con Enrique Delgado, cuando se levantó para ir a un teléfono privado, y regresó a decirnos que sí, que siguiéramos adelante con la reunión de ministros de Economía que se programaba en Managua. Al salir a la calle después de almorzar en el hotel, vi que los encabezados del periódico de la tarde anunciaban la invasión de territorio costarricense por fuerzas nicaragüenses. Tuve que llamar de inmediato por teléfono al ministro de Economía de Honduras, entonces presidente del CCEICA, para sugerirle aplazamiento.

En ocasión posterior, sin embargo, fue posible, después de consultas en San José, Costa Rica, organizar una reunión de ministros en Managua, a la que asistió Jorge Rossi, ministro costarricense, quien hasta tuvo que salir en una fotografía con el general Somoza y conmigo. En otra ocasión, después del asesinato del viejo Anastasio, tomó su lugar su hijo Luis Somoza, que era una persona tratable; al irlo a ver me dijo, literalmente, que él apoyaba la integración económica e industrial centroamericana, y: "Mirá, Víctor, vos me traés aquí a los principales industriales de Centroamérica y les decimos dónde poner sus fábricas, el asunto está resuelto".

En fin, los incidentes y anécdotas de este tipo eran frecuentes y empecé a dudar del éxito posible del programa. Consultaba yo con frecuencia con Wladislaw Malinowski en la sede de Naciones Unidas en Nueva York. Una vez fui invitado por el Secretario General, Dag Hammarskjld, a explicarle el programa. También lo expuse en Ginebra ante el profesor Gunnar Myrdal, Secretario Ejecutivo de la Comisión Económica de las Naciones Unidas para Europa, con sus asesores. Y, por supuesto, estaba en contacto constante con Raúl Prebisch y con Louis Swenson, en Santiago de Chile, quienes daban pleno apoyo a la Subsede y a veces casi carta blanca. Provocó alguna hilaridad el que una vez contestara yo un cablegrama con un lacónico: SUBSEDE CUMPLE. En 1957, durante el período de sesiones de la CEPAL en La Paz, Bolivia, llegué, a pesar mío, a la conclusión, por ésas y otras razones que tenían que ver con el estudio de la CEPAL sobre el desarrollo económico de México que había estado bajo la dirección de Celso Furtado y que no había sido del gusto de Prebisch, de que me sería indispensable en momento oportuno futuro separarme de la CEPAL y regresar a ocuparme de asuntos mexicanos en México, de los 
que había estado bastante alejado. Además, me la pasaba viajando de 5 a 6 meses de cada año. Avisé con un año de anticipación a Raúl Prebisch, para poder cumplir con el compromiso de la firma del primer Tratado de Libre Comercio en Tegucigalpa en junio de 1958 (a la cual él no pudo asistir).

Todas las etapas de este largo proceso de integración de América Central están debidamente documentadas, tanto en la CEPAL como en otros organismos. La bibliografía es larga. 3 / No ha sido el propósito de este ensayo analizar todo el fenómeno de la integración. En Guatemala se estableció la Secretaría de la Integración Económica Centroamericana (SIECA), que yo mismo en algún momento aconsejé crear para que los propios centroamericanos tomaran en sus manos la ejecución de las políticas de integración, sin dejar de tener asesoramiento de CEPAL y otros organismos del sistema de las Naciones Unidas. SIECA produjo muchos documentos de gran importancia e intervino en negociaciones después de 1960. Además, sistematizó la estadística.

Me desligué, sin embargo, intelectual y emotivamente, de la integración económica centroamericana, hasta mayo de 1987, cuando efectuamos en El Colegio de México un seminario sobre las integraciones regionales, promovido por Alexandre Stakhovitch, de la Comunidad Económica Europea, y por mí en que se presentaron estudios de comparación de procesos de integración en Europa, América Latina, Asia y Africa; copresidieron Felipe Herrera y Angel Viñas (reemplazado éste por Edwan Fouéré, ambos funcionarios de la Comisión de la CEE). Además de evaluar todos los procesos e instrumentaciones conocidos de la integración en cuatro continentes, tocó su turno a Centroamérica con ponencias de Gert Rosenthal, Raúl Sierra Franco y Gabriel Siri, que me parecieron demasiado optimistas. 4 / Hace uno o dos años vi en la TV a los cinco presidentes de Centroamérica hablando de la nueva integración centroamericana; eran las mismas frases, las mismas palabras, con que se expresaban en los años cincuenta y sesenta los presidentes y funcionarios de aquella época. Plus a change..

Creo haber podido conocer bastante bien a Centroamérica y Panamá en aquel tiempo de los años cincuenta. Hice muchos recorridos por tierra en auto y en jeep, por vía fluvial y por avión; hablé con cientos de personas en cada país. En la Subsede éramos un grupo con mucha cohesión, dedicados al ideal de la integración centroamericana, nunca por encima de las voluntades de los actores regionales y locales. Se contó con la colaboración de docenas de expertos del Sistema de las Naciones Unidas, de distintas nacionalidades.

Mi curiosidad me llevó incluso a hacer una visita de trabajo a Belice cuando era todavía colonia británica, en 1956, hecha con sigilo para evitar cualquier posible reacción de algún funcionario del Ministerio de Relaciones de Guatemala, que siempre veían con suspicacia que un mexicano fuera el director de la Subsede, a cargo de los estudios y actividades de integración centroamericana; después de cinco días de recorrer zonas agrícolas y forestales, salí por Chetumal, enteramente inadvertido. Belice alcanzó después su independencia, pero no parece que se le tome en cuenta en el "istmo centroamericano", por considerarlo un país del área del Caribe. La Centroamérica de cinco naciones contaba en 1960 con 11 millones de habitantes; preveíamos su duplicación en 25 años (se registraron 24 millones en 1985, y se estima llegar a 32 
millones para el año 2000. ¿Se habrá previsto la relación de este dato con un posible desarrollo económico y social integrado, que ahora, además, debiera ser sustentable?

Notas:

1/ Raúl Prebisch, Ël patrón oro y la vulnerabilidad económica de nuestros países", serie Jornadas (No. 11), El Colegio de México, 1944.

2/ El Dr. Charles Carreras me entregó un capítulo titulado "The U.S. Debate over Support for the Central American Common Market, 1958-1959", para un libro de él en preparación; dispongo de copia del texto respectivo, que se discutió, con mi participación, en sesión de la Latin American Studies Association(LASA) en Atlanta, Georgia, en 1994, organizada por Victor Bulmer-Thomas, del Instituto de Estudios Latinoamericanos de Londres.

3/ Véanse, entre otros, los libros y artículos de Eduardo Lizano, Carlos Manuel Castillo, Alberto Fuentes Mohr, Gert Rosenthal, Isaac Cohen, Raúl Sierra Franco, y tantos más, y las muy extensas bibliografías en ellos citadas.

4/ Víctor L. Urquidi y Gustavo Vega Cánovas (comps.) "Unas y otras integraciones", serie Lecturas, $N^{\prime} 72$, México, D.F., Fondo de Cultura Económica, 1991. El título se tomó de la ponencia póstuma de Alexandre Stakhovitch (nuestro querido amigo "Stako", cepalino de los años cincuenta), quien había fallecido poco antes en un accidente aéreo en Tikal, Guatemala. 